\title{
Rise of the machines
}

Shaun Sellars continues his series on ethical dilemmas in dentistry

which appears in every second issue of the BDJ.

The current trend for 'do-it-yourself orthodontics' appears to be inescapable. A growing number of companies are attempting to cut out the middle man by selling the dream of straight teeth to their customers. This has naturally, and rightly, been decried in dental circles.

This column isn't about that. It's about what might be next.

Direct to consumer orthodontics has come about through advances in technology which allow the vast majority of this complex treatment to be fully, or mostly automated. The patient may never see a dentist.

If orthodontics, one of the most complex forms of dental treatment, is susceptible to deskilling and digital redundancy, where will that leave the rest of the profession in the future?

We're already seeing scanners, milling machines and $3 \mathrm{D}$ printers enter into practice. The technology is there for AI-assisted note-taking. As patients' ability to control their treatment increases, where does that leave the general dentist?

Imagine a scenario in the not too distant future where we have an accurate and reliable way to detect caries using a handheld device, much like current $3 \mathrm{D}$ scanners. Add in a little machine learning and these devices could soon become better at detecting dental disease than any dentist. From this, it's a relatively simple step to suggest treatment options.

So far so good. Improved diagnostics and better outcomes for patients. This may well be something that a large group of the profession can get behind. As time goes by this technology naturally becomes more affordable and smaller. More dentists will have access to it. But what happens when it's so easy to use, that you don't need to be a dentist to do it.

Eventually, someone comes up with the idea of integrating this into a toothbrush. Every day, patients can assess the health of their mouth directly whenever they want. They can tell if they need to see a dentist and get tips on how to look after their teeth

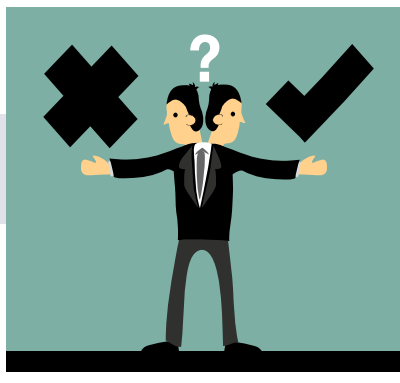

themselves. They can cut out the middle man. The silicon dentist in their toothbrush tells them that they need to see the flesh and bones dentist in the surgery. It even books you an appointment and suggests what treatment you may want to opt for.

This may seem far off, but it wasn't that long ago that if you wanted to take a picture, you had to have a dedicated camera. Technology is adapting faster than many of us can take in. These changes are going to bring about new ethical dilemmas and concerns which we should all be involved in tackling. Not least of these is how far do we let this go? Are we happy letting computers dictate our choices of treatment, and what happens when those computers are advanced enough to carry that treatment out? To sift through this we need to be able to accurately predict the future or be involved in shaping it. Sitting back and letting it happen isn't an option.

\section{Shocking lack of awareness of HPV}

One in every 20 cancers is caused by the human papillomavirus (HPV). Despite this, nearly half of Brits (47\%) have not heard of HPV while almost two-thirds (63\%) do not know how it is transmitted.

These findings have been revealed by the Oral Health Foundation, who are increasingly concerned by how little we know about HPV as a population.

Latest figures show that around 18,000 cancers were diagnosed as HPV related in the UK last year. These include cancer of the mouth, cervix, anus and penis.

Many health experts are pointing to HPV as the main reason why cases of mouth cancer have more than doubled inside the last generation.

HPV types 16 and 18 are linked to around three quarters $(73 \%)$ of oropharyngeal cancers. HPV is also linked to more than one-in-ten (12\%) cancers in the tongue, tonsils and roof of the mouth.

HPV can be transmitted via oral sex and for most people, does not have any symptoms. This means many sexually-active people can be infected with HPV and not realise it. For a small number of people, HPV can lead to cancer.

The Oral Health Foundation's research, as part of November's Mouth Cancer Action Month, also found nearly four in-five (79\%) are unaware that oral sex can raise their risk of mouth cancer through the contraction of HPV.

Dr Nigel Carter OBE, Chief Executive of the Oral Health Foundation, said: 'The surest way to be protected from HPV is to have a vaccination. So far, this has been offered to girls in year 8 from 2007 and boys since September 2019. Everybody who remains unvaccinated should be aware of the risks posed by HPV. Sexually-active people should be vigilant to any changes in their mouth so they can catch mouth cancer early if it does develop'

Peter Baker, Campaign Director of HPV Action, wrote to Professor Andrew Pollard, Chair of the Joint Committee on Vaccination and Immunisation at Public Health England (JCVI) on 24 October, urging the JCVI to reconsider its decision not to introduce a catch-up programme for boys who are too old to receive the $H P V$ vaccination when they are in year 8 (which was introduced in September 2019). In the letter shared with the BDJ, Peter Baker wrote 'We believe that an opportunity is being missed to protect a very significant number of boys who, without vaccination, will be left at risk of HPV-caused diseases. [...] We urge you to re-consider this issue at the JCVI's meeting in February 2020. A positive decision would leave enough time for implementation of a catch-up programme from September 2020'. 